\title{
Sound Transmission Prediction of Sandwich Plates With Honeycomb and Foam Cores and an Emphatic Discussion on Radiation Terms
}

\author{
Tong Zhang, Ludi Kang, Xin Li, Hongbo Zhang and Bilong Liu \\ School of Mechanical and Automobile Engineering, Qingdao University of Technology, No.777 Jialingjiang Road, \\ Qingdao 266520, China.
}

\begin{abstract}
(Received 19 September 2020; accepted 18 December 2020s)
When applying the modal summation method to the sound transmission loss (STL) prediction of various plates, the assumption of the blocked sound pressure, or alternatively speaking, ignoring sound radiation terms, has obvious simplicity and is sometimes used for the single-layered panels, rib-stiffened plates or heavily damped sandwich plates. For light-weighted sandwich plates with honeycomb and foam cores, however, this assumption is somewhat in doubt and worth examining. Based on sixth-order differential equations governing the flexural vibration of sandwich plates, the prediction formula of STL is derived by the modal summation approach. Theoretical predictions were validated by measurement data. Next, the theoretical formula of STL under the assumption of the blocked sound pressure was examined. The STL discrepancies of sandwich plates caused by sound radiation terms are illustrated. It was found that the STL discrepancies of sandwich plates were closely related to frequency, reached their peak value at the coincidence frequency region. The results indicate that the sound radiation terms, or the couplings between the radiated sound pressure and the plate response, should not be ignored for the prediction of STL for sandwich plates with honeycomb and foam cores.
\end{abstract}

\section{NOMENCLATURE}

$\begin{array}{ll}w & \text { lateral displacement of plate } \\ \beta_{x} & \text { angular displacements } \\ \beta_{y} & \text { angular displacements } \\ D_{1} & \text { static stiffness of the entire structure } \\ D_{2} & \text { bending stiffness of the face sheet } \\ I_{\omega} & \text { mass moment of inertia } \\ E_{1} & \text { Young modulus of the face sheet } \\ E_{2} & \text { Young modulus of the core } \\ v_{c} & \text { Poisson ratio of the core } \\ v_{l} & \text { Poisson ratio of the face sheet } \\ \mu & \text { mass per unit area of the entire plate } \\ G & \text { effective shear modulus of the core } \\ H & \text { thickness of the core } \\ h & \text { thickness of one face sheet } \\ p^{i} & \text { incident sound pressure of the plate } \\ p^{t} & \text { transmitted sound pressure of the plate }\end{array}$

\section{INTRODUCTION}

Sandwich plates with a honeycomb core have the advantage of being light weight, having a high specific strength and provide excellent vibration reducing performance. They are widely used in the automobile and construction industries. Although sandwich plates have many advantages, the STL may be worse than the single-layered panels with the same weight. In order to design acoustically superior sandwich plates, it is worth developing an efficient tool to predict the STL of sandwich plates.

The STL of sandwich plates has been investigated by many scholars. $^{1-8}$ As early as 1959, Kurtze and Watters used a model based on the mechanical impendence of each layer to describe the bending of the plate. They suggested that a welldesigned sandwich plate could provide a better sound insulation property than a homogenous plate with equivalent mass. ${ }^{1}$
The model was later improved by Dym and Langwhen they decoupled the motion of the system into symmetric motion and antisymmetric motion and predicted the STL of the sandwich plate. $^{2}$ Lang and Dym also put forth a method to improve the STL of the sandwich plate. ${ }^{3}$ Taking the surface density of sandwich plates as the constraint condition, the constrained optimization method was used to optimize the design of sound insulation characteristics. Ford et al. studied the influence of core material characteristics on the inherent frequency of symmetric vibration mode, measured the STL of two sandwich plates with homogeneous core, and explained the phenomenon of STL reduction with the theoretical estimation of inherent frequency. ${ }^{4}$ Nilsson studied the acoustic characteristics of the sandwich structure with a homogeneous elastic core. ${ }^{5}$ Subsequently, Nilsson considered the bending, shearing and rotation of the core layer and developed the theoretical model for vibroacoustical analysis based on Hamilton's principle. ${ }^{6}$ In his paper, bending stiffness and loss factor were related not only to material parameters and plate geometry, but also to frequency. Thamburaj and Sun deduced the STL according to the vertical displacement of the sandwich beam. ${ }^{7,8}$ For the sandwich plate with anisotropic core, the research showed that in the frequency range of $10 \sim 1000 \mathrm{~Hz}$, the pull-shear coupling effect of anisotropic core can effectively improve the STL. However, only the incident sound pressure was used as an excitation, so the effects of reflection and radiation pressure were ignored.

In the above studies, sandwich plates are mostly considered as infinite plates, while the actual dimensions of sandwich plates are usually limited. The influence of component size on sound insulation can be found in reference. 9 The relationship between the acoustic transmission coefficients of finite plates and infinite plates below the coincidence frequency is known, but this is only a conclusion for single-layered isotropic panels. Takahashi discussed the influence of boundedness of plate on STL, established sound insulation theory of finite width and 
infinite length plate in rigid baffle, and obtained a frequency characteristic curve. ${ }^{10}$ However, it seems difficult to evaluate the STL of plates using strict results, as they have sharp peaks and troughs due to resonance. Lee et al. analyzed the STL of the finite large sandwich plate based on the modal summation method. ${ }^{11}$ However, in Lee's model, only the blocked sound pressure was used as excitation, and the couplings between the radiated sound pressure and the plate response were neglected. Lok and Cheng studied the STL of an equivalent thick plate under different boundary conditions, but their study only focused on the structural vibration of the sandwich plate and did not consider the acoustic radiation. ${ }^{12,13}$ Du studied sandwich plates with a viscoelastic damping layer and found that, in the low frequency range, the high damping of viscoelastic layer is beneficial to eliminate the low-order modal resonance of small plates and significantly improves the STL. ${ }^{14}$ When the plate grows to a certain size, the loss of sound transmission is governed by the mass law even in the low frequency range. For honeycomb sandwich plates, it is necessary to compare the sound insulation prediction results of finite and infinite sizes. ${ }^{15}$ Qian et al. predicted the STL of finite sandwich plates with honeycomb cores based on a test procedure on beam elements, and found that the forecast results of the finite large models showed many fluctuations at low frequencies compared with the infinite large models. ${ }^{16}$ For the accurate prediction of the STL of honeycomb sandwich plates, the damping caused by acoustic radiation is very important. The orthogonality may play a slight effect on the STL of sandwich plates. In the 26th ICSV distinguished plenary lecture, Liu reviewed the ongoing efforts to improve sound insulation for light-weight structures. ${ }^{17}$ He pointed out that accurate prediction tools and new understanding of the vibro-acoustic properties of lightweight sandwich structures under various excitations are also useful and worth investigating.

The sound insulation property of honeycomb and foam core sandwich structures are very different from that of a singlelayered panel. The influence of radiation terms on the sound transmission through sandwich plates with honeycomb and foam cores has not been discussed in detail in the literature. In many cases, for example, as for single-layered plates, ribstiffened plates and heavily damped sandwich plates, the influence may not be important and can be neglected. For simplicity, when applying the modal summation method, the assumption of the blocked sound pressure is often used, for example, with the study of sound insulation for heavily damped sandwich plates and rib-stiffened plates. ${ }^{11,18}$ For sandwich plates with honeycomb and foam cores, however, this assumption is somehow doubtful and worth examining. Based on the sixthorder differential equation governing the flexural vibration of sandwich plates, through the transformation between physical coordinates and modal coordinates, a series of single-degreeof-freedom equations in a modal coordinate system are decoupled from the prime dynamic equations. ${ }^{19}$ Then the system response in the original physical coordinate system is obtained by superimposing the contributions of each mode, and the theoretical formula of honeycomb sandwich structure STL is derived. The effects of shear modulus and loss factor of the core and surface density were studied. The theoretical formula of STL by ignoring sound radiation terms $2 p^{t}$ is illustrated. Additionally, the influence of parameters on the discrepancies of STL caused by the sandwich plate ignoring sound radiation terms is discussed.

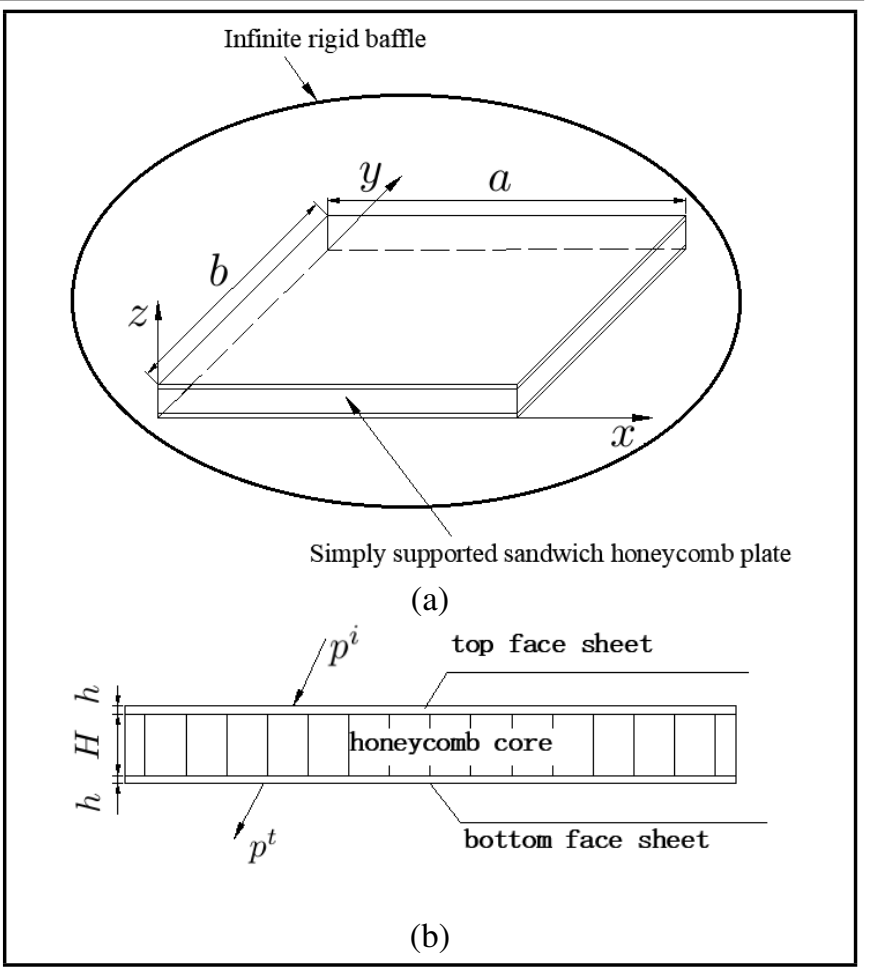

Figure 1. Schematic of sound transmission through a rectangular sandwich plate which is simply supported on its edges (a) global view; (b) section diagram of the rectangular sandwich plate.

\section{THEORY FOR STL}

The derivation process of a theoretical model is presented in this section. Then, the theoretical formula of STL ignoring sound radiation terms $2 p^{t}$ is derived.

\subsection{STL of Sandwich Plate}

The sandwich plate in this research refers to a structure consisting of two aluminum sheets connected to a honeycomb core of hexagon cells or aluminum foam. This structure is considered to be symmetrical.

Consider a simply supported, rectangular sandwich plate occupying the region $0 \leq x \leq a, 0 \leq y \leq b$ within an infinite rigid baffle. Sound enters from one side and travels through the plate to the other, as shown in Fig. 1.

Nilsson considered the bending, shearing and rotation of the sandwich structure in his model. ${ }^{19}$ The differential equation of the rectangular plate is derived by using Hamilton's principle, as shown below:

$$
\begin{aligned}
-D_{1}\left[\frac{\partial^{2} \beta_{x}}{\partial x^{2}}+\right. & \left.\frac{1}{2}\left(\frac{\partial^{2} \beta_{x}}{\partial y^{2}}+\frac{\partial^{2} \beta_{y}}{\partial x \partial y}\right)\right] \\
+D_{2}\left(2 \frac{\partial^{3} w}{\partial x^{3}}-\right. & \left.2 \frac{\partial^{2} \beta_{x}}{\partial x^{2}}+2 \frac{\partial^{3} w}{\partial x \partial y^{2}}-\frac{\partial^{2} \beta_{x}}{\partial y^{2}}-\frac{\partial^{2} \beta_{y}}{\partial x \partial y}\right) \\
& +G H\left(\beta_{x}-\frac{\partial w}{\partial x}\right)+I_{\omega} \frac{\partial^{2} \beta_{x}}{\partial t^{2}}=0
\end{aligned}
$$

$$
\begin{gathered}
2 D_{2}\left(\frac{\partial^{4} w}{\partial x^{4}}+2 \frac{\partial^{4} w}{\partial x^{2} \partial y^{2}}+\frac{\partial^{4} w}{\partial y^{4}}-\frac{\partial^{3} \beta_{x}}{\partial x^{3}}-\frac{\partial^{3} \beta_{y}}{\partial y^{3}}\right. \\
\left.-\frac{\partial^{3} \beta_{x}}{\partial x \partial y^{2}}-\frac{\partial^{3} \beta_{y}}{\partial x^{2} \partial y}\right)+G H\left(\frac{\partial \beta_{x}}{\partial x}+\frac{\partial \beta_{y}}{\partial y}\right. \\
\left.-\frac{\partial^{2} w}{\partial x^{2}}-\frac{\partial^{2} w}{\partial y^{2}}\right)+\mu \frac{\partial^{2} w}{\partial t^{2}}=2 p^{i}-2 p^{t}
\end{gathered}
$$




$$
\begin{gathered}
-D_{1}\left[\frac{\partial^{2} \beta_{y}}{\partial y^{2}}+\frac{1}{2}\left(\frac{\partial^{2} \beta_{y}}{\partial x^{2}}+\frac{\partial^{2} \beta_{x}}{\partial x \partial y}\right)\right] \\
+D_{2}\left(2 \frac{\partial^{3} w}{\partial y^{3}}-2 \frac{\partial^{2} \beta_{y}}{\partial y^{2}}+2 \frac{\partial^{3} w}{\partial y \partial x^{2}}-\frac{\partial^{2} \beta_{y}}{\partial x^{2}}-\frac{\partial^{2} \beta_{x}}{\partial x \partial y}\right) \\
+G H\left(\beta_{y}-\frac{\partial w}{\partial y}\right)+I_{\omega} \frac{\partial^{2} \beta_{y}}{\partial t^{2}}=0 \\
D_{1}=\frac{E_{2}}{\left(1-\nu_{c}^{2}\right)} \frac{H^{3}}{12}+\frac{E_{1}}{\left(1-\nu_{l}^{2}\right)}\left(\frac{H^{2} h}{2}+H h^{2}+\frac{2 h^{3}}{3}\right) \\
D_{2}=\frac{E_{1}}{\left(1-\nu_{l}^{2}\right)} \frac{h^{3}}{12} \\
I_{\omega}=\rho_{c} H^{3} / 12+\rho_{l}\left(H^{2} h / 2+H h^{2}+2 h^{3} / 3\right) \\
\mu=2 h \rho_{l}+H \rho_{c} .
\end{gathered}
$$

Simple eigenfunctions can be formulated describing the vibration of a rectangular sandwich plate, which is simply supported along all four boundaries. Displacement $w$, angular displacements $\beta_{x}$ and $\beta_{y}$ can be expressed as:

$$
\begin{aligned}
\beta_{x}(x, y, t) & =\sum_{m n} B_{m n} \cos (\varepsilon x) \sin (\eta y) e^{i \omega t} \\
w(x, y, t) & =\sum_{m n} A_{m n} \sin (\varepsilon x) \sin (\eta y) e^{i \omega t} \\
\beta_{y}(x, y, t) & =\sum_{m n} C_{m n} \sin (\varepsilon x) \cos (\eta y) e^{i \omega t} .
\end{aligned}
$$

$A_{m n}, B_{m n}, C_{m n}$ are the amplitudes of displacements and angular displacements. $\epsilon=\frac{m \pi}{a}, \eta=\frac{n \pi}{b}$.

Substituting Eqs. (8) to (10) into Eqs. (2) to (3), the following relation can be derived:

$$
\begin{aligned}
& B_{m n}=R_{m n} A_{m n} ; \\
& C_{m n}=S_{m n} A_{m n} ;
\end{aligned}
$$

where:

$$
\begin{gathered}
\text { where: } \\
R_{m n}=\frac{P N-F Q}{T N-F M} ; \\
S_{m n}=\frac{P M-T Q}{F M-T N} \\
T=D_{1}\left(\varepsilon^{2}+\frac{1}{2} \eta^{2}\right)+D_{2}\left(2 \varepsilon^{2}+\eta^{2}\right)+G H-\omega^{2} I_{\omega} ; \\
F=\frac{1}{2} D_{1} \varepsilon \eta+D_{2} \varepsilon \eta ; \\
M=\frac{1}{2} D_{1} \varepsilon \eta+D_{2} \varepsilon \eta-\omega^{2} I_{\omega} ; \\
N=D_{1}\left(\frac{1}{2} \varepsilon^{2}+\eta^{2}\right)+D_{2}\left(\varepsilon^{2}+2 \eta^{2}\right)+G H ; \\
P=D_{2}\left(2 \varepsilon^{3}+2 \eta^{2} \varepsilon\right)+G H \varepsilon ; \\
Q=D_{2}\left(2 \varepsilon^{2} \eta+2 \eta^{3}\right)+G H \eta ;
\end{gathered}
$$

substituting Eqs. (11) and (12) into Eq. (1), the following equation can be derived:

$$
\sum_{m n} J_{m n} A_{m n} \sin (\varepsilon x) \sin (\eta y)=2 p^{i}-2 p^{t}
$$

where:

$$
\begin{aligned}
& J_{m n}=2 D_{2}\left[\left(\varepsilon^{2}+\eta^{2}\right)^{2}-R_{m n}\left(\varepsilon^{3}+\varepsilon \eta^{2}\right)\right. \\
& \left.-S_{m n}\left(\eta^{3}+\varepsilon^{2} \eta\right)\right]+G H\left(\varepsilon^{2}+\eta^{2}-\varepsilon R_{m n}-\eta S_{m n}\right) \\
& -\omega^{2} \mu .
\end{aligned}
$$

The Eq. (21) is multiplied by $\sin (\varepsilon x) \sin (\eta y)$ on both sides and performs double integrals, then yields:

$$
J_{m n} A_{m n}=2 \mathrm{j} \omega\left(P_{m n}^{i}-P_{m n}^{t}\right) .
$$

When the surrounding fluid is air and does not consider the influence of mutual radiation modes. ${ }^{16}$

$$
P_{m n}^{t} \approx \rho_{0} c_{0} \sigma_{m n} A_{m n}
$$

Here, the modal radiation coefficient $\sigma_{m n}$ by literature. ${ }^{20}$

$$
\begin{aligned}
& \sigma_{m n}=\frac{64 k^{2} a b}{\pi^{6} m^{2} n^{2}} \\
& \cdot \int_{0}^{\frac{\pi}{2}} \int_{0}^{\frac{\pi}{2}}\left\{\frac{\left(\frac{\cos }{\sin }\right)^{\left(\frac{\alpha}{2}\right)}\left(\frac{\cos }{\sin }\right)^{\left(\frac{\beta}{2}\right)}}{\left[\left(\frac{\alpha}{m \pi}\right)^{2}-1\right]^{2}\left[\left(\frac{\beta}{n \pi}\right)^{2}-1\right]^{2}}\right\}^{2} \sin \theta d \theta d \varphi .
\end{aligned}
$$

Substitute (24) into (23) to get the modal amplitude:

$$
A_{m n}=\frac{2 \mathrm{j} \omega P_{m n}^{i}}{J_{m n}+2 \mathrm{j} \omega \rho_{0} c_{0} \sigma_{m n}}=Y_{s, m n} P_{m n}^{i}
$$

where, $Y_{s, m n}$ is generally called structure modal admittance.

The STL under the diffuse sound field is obtained as: ${ }^{21}$

$$
T L=-10 \log _{10}\left[\frac{4 \pi\left(\rho_{0} c_{0}\right)^{2}}{a b k^{2}} \sum_{m=1}^{M} \sum_{n=1}^{N} \sigma_{m n}^{2}\left|Y_{s, m n}\right|^{2}\right]
$$

where, $M$ and $N$ are the truncated modal number used in the calculation.

\subsection{STL of Plate Ignoring the Sound Radiation Terms}

The assumption of the blocked sound pressure, or alternatively speaking, ignoring sound radiation terms $2 p^{t}$, is often used for the prediction of the STL of single-layered plates, rib-stiffened plated or heavily damped sandwich plates. This assumption is somehow reasonable for relatively heavy and damping plates since in these cases the couplings between the radiated sound pressure and the plate response can be neglected. For sandwich plates with honeycomb and foam cores, the validation of this assumption is worth discussing for the prediction of STL. 
If the radiation terms $2 p^{t}$ are ignored in Eq. (1), Eq. (1) is changed to:

$$
\begin{gathered}
2 D_{2}\left(\frac{\partial^{4} w}{\partial x^{4}}+2 \frac{\partial^{4} w}{\partial x^{2} \partial y^{2}}+\frac{\partial^{4} w}{\partial y^{4}}\right. \\
\left.-\frac{\partial^{3} \beta_{x}}{\partial x^{3}}-\frac{\partial^{3} \beta_{y}}{\partial y^{3}}-\frac{\partial^{3} \beta_{x}}{\partial x \partial y^{2}}-\frac{\partial^{3} \beta_{y}}{\partial x^{2} \partial y}\right) \\
+G H\left(\frac{\partial \beta_{x}}{\partial x}+\frac{\partial \beta_{y}}{\partial y}-\frac{\partial^{2} w}{\partial x^{2}}-\frac{\partial^{2} w}{\partial y^{2}}\right)+\mu \frac{\partial^{2} w}{\partial t^{2}}=2 p^{i} .
\end{gathered}
$$

After ignoring sound radiation, Eq. (21) is changed to:

$$
\sum_{m n} J_{m n} A_{m n} \sin (\varepsilon x) \sin (\eta y)=2 p^{i} .
$$

By using the same method as Eq. (23), Eq. (29) is replaced by:

$$
J_{m n} A^{*}{ }_{m n}=2 \mathrm{j} \omega P_{m n}^{i} .
$$

The modal amplitude is changed to:

$$
A^{*}{ }_{m n}=\frac{2 \mathrm{j} \omega P_{m n}^{i}}{J_{m n}}=Y_{s, m n}^{*} P_{m n}^{i} .
$$

Modal admittance of sandwich plate is changed to:

$$
Y_{s, m n}^{*}=\frac{2 \mathrm{j} \omega}{J_{m n}} .
$$

After ignoring sound radiation, the STL of the honeycomb sandwich plate is:

$$
T L=-10 \log _{10}\left[\frac{4 \pi\left(\rho_{0} c_{0}\right)^{2}}{a b k^{2}} \sum_{m=1}^{M} \sum_{n=1}^{N} \sigma_{m n}^{2}\left|Y_{s, m n}^{*}\right|^{2}\right] .
$$

For simply supported single-layered panel (surrounded by infinite baffle), structural admittance $Y_{m n}$ can be expressed as: ${ }^{21}$

$$
Y_{m n}=\frac{2 \mathrm{j} \omega}{m_{p}\left[\omega_{m n}^{2}(1+\mathrm{j} \eta)-\omega^{2}\right]+2 \mathrm{j} \omega \rho_{0} c_{0} \sigma_{m n}} .
$$

Using the same method as above, the structural admittance ignoring sound radiation terms $2 p^{t}$ is changed to:

$$
Y_{m n}^{*}=\frac{2 j \omega}{m_{p}\left[\omega_{m n}^{2}(1+\mathrm{j} \eta)-\omega^{2}\right]} .
$$

The change of structural admittance considering or ignoring sound radiation terms leads to the change of STL. After ignoring the sound radiation terms, the STL of a single-layered panel is:

$$
T L=-10 \log _{10}\left[\frac{4 \pi\left(\rho_{0} c_{0}\right)^{2}}{a b k^{2}} \sum_{m=1}^{M} \sum_{n=1}^{N} \sigma_{m n}^{2}\left|Y_{m n}^{*}\right|^{2}\right] .
$$

\section{VERIFICATION AND ANALYSIS}

\subsection{Comparison of Theoretical Prediction and Experimental Data}

The honeycomb sandwich plates are symmetrical in structure and consist of two thin sheets bonded to a honeycomb core of hexagon cells. The sheets and the core are made of
Table 1. Properties of honeycomb sandwich plates tested.

\begin{tabular}{||c|c|c|c|c|}
\hline Plate & $\begin{array}{c}\text { Honeycomb } \\
\text { cell size }(\mathrm{mm})\end{array}$ & $\begin{array}{c}\text { Size of test } \\
\text { plates }(\mathrm{mm})\end{array}$ & $\begin{array}{c}\text { Surface } \\
\text { density }\left(\mathrm{kg} / \mathrm{m}^{2}\right)\end{array}$ & $\begin{array}{c}h / H / h \\
(\mathrm{~mm})\end{array}$ \\
\hline $\mathrm{A}$ & 6.4 & $1110 \times 1250$ & 8.51 & $1.4 / 13.2 / 1.4$ \\
\hline $\mathrm{B}$ & 7.2 & $1110 \times 1250$ & 11.32 & $1.8 / 22.2 / 1.8$ \\
\hline
\end{tabular}

aluminum. The parameters of the honeycomb sandwich plates are shown in Table $1 .{ }^{16}$

The Young modulus of the face sheet is $71 \mathrm{GPa}$, and Poisson ratio of the face sheet is 0.35 . The Young modulus of the core is $780 \mathrm{MPa}$, the shear modulus of the core is $840 \mathrm{MPa}$, and the Poisson ratio of the core is 0.3 . The selection of the loss factor here refers to the measurement result of similar structural loss factor. Considering that it is difficult to accurately measure the structural loss factor at high frequencies, for simplicity, hereafter the structural loss factor $f(x)$ is fitted with point $(300,0.03),(1000,0.02),(5000,0.01),(10000,0.005)$ at high frequencies. The relation between structural loss factor and frequency of honeycomb sandwich plate is expressed by Eq. (37) except noted otherwise.

$$
f(x)=\left\{\begin{array}{cc}
0.03 & x \leq 300 H z \\
0.01918 \exp (-0.001821 x) & x \geq 300 H z \\
+0.01964 \exp (-0.0001388 x) &
\end{array}\right.
$$

The comparison between theoretical prediction and experimental data is shown in Fig. 2. For a comparison, the mass lass with a correction factor added for a small plate is also plotted according to ISO 15186-3, Annex A. There are some differences between the measured values and predicted values of plate $\mathrm{A}$ in the low frequency area, and the values match well in high frequency area, as illustrated in Fig. 2(a). The boundary conditions used in the experiment are between simply supported and fully clamped, and the theoretical predictions are based on the simply supported boundary conditions, which may lead to the differences between theoretical calculation and experiment results. In general, it is believed that the maximum influence of boundary on sound insulation is $3 \sim 4 \mathrm{~dB}$ in the low frequency area. The differences are mainly manifested in the $400 \sim 1100 \mathrm{~Hz}$ frequency domain, the cause of this differences may be that the modal radiation coefficient used in theoretical calculation is lower than the actual value. Therefore, the accurate calculation of the modal radiation coefficient is very important for the accurate prediction of sound insulation near the coincidence frequency region.

For the thicker plate B, the predicted values are lower than the experimental values at the coincidence frequency region, as illustrated in Fig. 2(b). Because of the special structure of the honeycomb sandwich plate, the static bending rigidity of the sandwich plate is much higher than that of a homogeneous aluminum panel with the same surface density. Using plate $\mathrm{A}$ as an example, the static bending stiffness is about $8000 \sim 9000 \mathrm{~N} / \mathrm{m}$, and the stiffness of the single-layered aluminum panel with the same surface density is only $170 \mathrm{~N} / \mathrm{m}$. For finite sandwich honeycomb plates, high bending stiffness leads to low coincidence frequency in Fig. 2. The coincidence frequency of plate $\mathrm{A}$ is about $800 \mathrm{~Hz}$, while that of aluminum plate with the same surface density is about $3870 \mathrm{~Hz}$. This should be the reason for the decrease of transmission loss near the coincidence frequency region. For finite sandwich honeycomb panels, high bending stiffness results in reduced modal density. The effect of individual modes on acoustic radiation is 


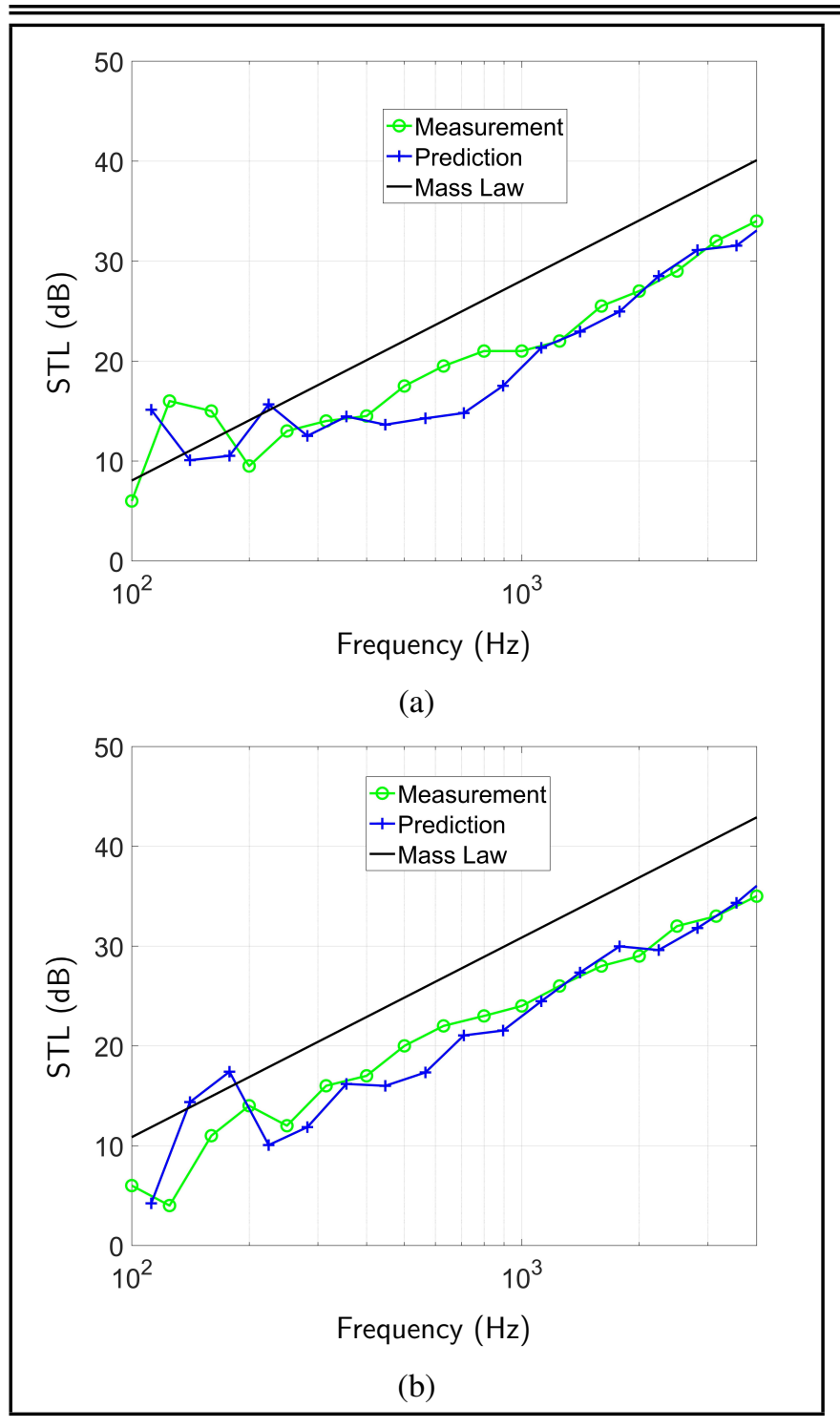

Figure 2. Comparison between experimental data and theoretical prediction (a) Plate A; (b) Plate B (1/3 octave band).

Table 2. Properties of aluminum foam sandwich plates tested.

\begin{tabular}{|c|c|c|c|c|}
\hline Plate & $\begin{array}{c}\text { Porosity of } \\
\text { aluminium foam }\end{array}$ & $\begin{array}{c}\text { Size of test } \\
\text { plates }(\mathrm{mm})\end{array}$ & $\begin{array}{c}\text { Surface } \\
\text { density }\left(\mathrm{kg} / \mathrm{m}^{2}\right)\end{array}$ & $\begin{array}{c}h / H / h \\
(\mathrm{~mm})\end{array}$ \\
\hline C & $84 \%$ & $839 \times 839$ & 10.8 & $1.25 / 9.5 / 1.25$ \\
\hline $\mathrm{D}$ & $84 \%$ & $839 \times 839$ & 14.5 & $1.25 / 19.5 / 1.25$ \\
\hline
\end{tabular}

more significant, especially at low frequency. This should be the reason why there is some dips of transmission loss below the coincidence frequency region.

The theoretical prediction is also compared with the experimental data of aluminum foam sandwich plate. The plates are symmetrical in structure and consist of two thin sheets bonded to an aluminum foam core. The parameters of the aluminum foam sandwich plates are shown in Table $2 .^{22}$

The Young modulus of core is $106 \mathrm{MPa}$, the shear modulus of core is $35 \mathrm{MPa}$, and Poisson ratio of core is 0.3 . The experimental results and theoretical calculations show good agreement in the low frequency and some differences in the high frequency, as illustrated in Fig. 3. For the aluminum foam sandwich plate, the loss factor has a great influence on sound insulation in the high frequency. Theoretical prediction underestimates the STL of such sandwich plate in comparison with experimental results. The reason for this might be the underes-

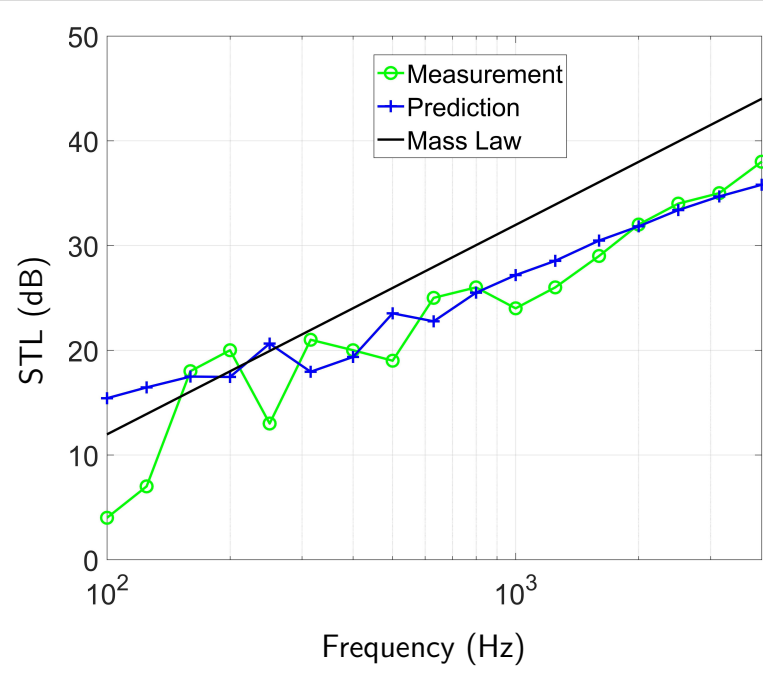

(a)

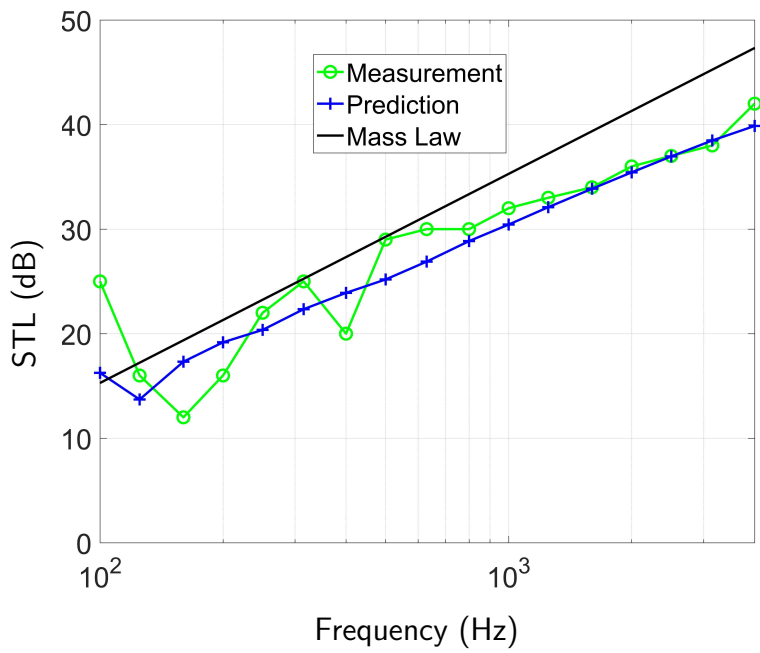

(b)

Figure 3. Comparison between experimental data and theoretical prediction (a) Plate C; (b) Plate D (1/3 octave band).

timation of the structural loss factor and the acoustic radiation loss factor. Therefore, accurate loss factor is the guarantee to accurately predict sound insulation.

Finally, a $1.5 \mathrm{~m} \times 1.2 \mathrm{~m}$ sandwich plate consisting of a core layer of polymethyl imide foam (PMI) and two $2 \mathrm{~mm}$ carbon fiber (CF) bonded panels is tested. The STL are measured according to the Acoustics-Measurement of sound insulation in buildings and of building elements-Part 3: Laboratory measurement of airborne sound insulation of building elements (ISO 140-3:1995, IDT). In the prediction, the Young modulus of the carbon fiber is adopted as $50 \mathrm{GPa}$, Poisson ratio 0.25. The Young modulus of PMI core is $62 \mathrm{MPa}$, the shear modulus of core is $35 \mathrm{MPa}$. The density of carbon fiber is $1600 \mathrm{~kg} / \mathrm{m}^{3}$, and the density of PMI core is $50 \mathrm{~kg} / \mathrm{m}^{3}$. The measured and predicted values of the sandwich plate are preferred in the frequency range of interest, as illustrated in Fig. 4.

The differences of theoretical values and experimental values in the whole frequency band could be caused by the inaccurate shear modulus and structural loss factor. It is also related to the failure to strictly meet the simply supported boundary conditions when testing the mounting components. Considering the theoretical predictions and experimental results of the honeycomb core and the aluminum foam core, and that the er- 


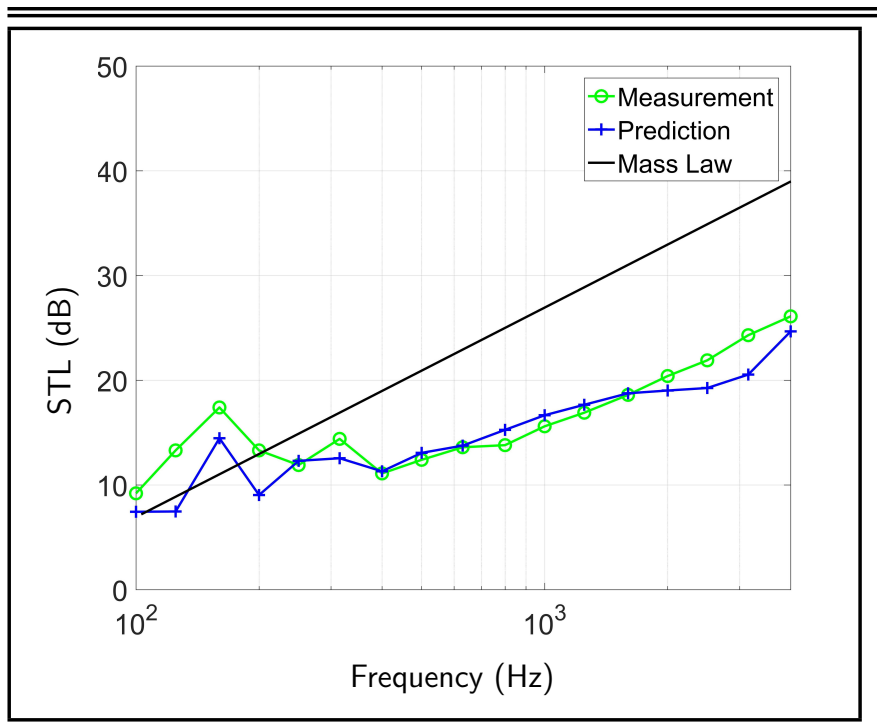

Figure 4. Comparison between experimental data and theoretical prediction $\left(2 \mathrm{~mm} \mathrm{CF}+30 \mathrm{~mm}\right.$ PMI $+2 \mathrm{~mm} \mathrm{CF}$, surface density $7.9 \mathrm{~kg} / \mathrm{m}^{2}, 1 / 3$ octave band).

ror estimation of the weighted single value sound insulation is within $1 \sim 2 \mathrm{~dB}$, it is reasonable to use this theory to predict the STL of the sandwich plate.

\subsection{Parameter Analysis of STL}

The effects of shear modulus, loss factor and thickness of the core on STL are further analyzed by using the principle of single variable.

The shear modulus of the core layer could be a problematic parameter in the experiment, because a standardized test requires a strain-stress test bench and complex setup. Therefore, it is necessary to study the influence of shear modulus on sound insulation. Parameter analysis takes plate A as the research object. When analyzing the influence of a single factor on STL, other parameters remain unchanged.

As shown in Fig. 5(a), the shear modulus of core layer has significant influence on the STL of a honeycomb sandwich plate. When the shear modulus is low $\left(8 \cdot 10^{6} \mathrm{~Pa}\right)$, upper and lower panels are well decoupled, and it is equivalent to a double plate, the sound insulation agrees well with the mass law over a large frequency range. However, when the shear modulus increases to $8 \cdot 10^{7} \mathrm{~Pa}$, sound insulation is significantly reduced. When the shear modulus continues to increase $\left(8 \cdot 10^{8} \mathrm{~Pa}\right)$, the sound insulation improves, and starts to move towards the mass law. When the shear modulus increases to $8 \cdot 10^{9} \mathrm{~Pa}$, the two sheets and core layer are strongly connected. This can be approximated as a homogeneous single-layered panel, and the sound insulation continues to increase, but not to the level of the mass law. In this case, changing the shear modulus of the core layer again has almost no influence on the sound insulation performance.

When the shear modulus increases from $8 \cdot 10^{6} \mathrm{~Pa}$ to $8 \cdot 10^{7} \mathrm{~Pa}$, there is an inflection point in sound insulation performance, as shown in Fig. 5(b). The reason is that the increase of shear modulus leads to the increase of bending stiffness of the sandwich plate, then the coincidence frequency of the plate decreases and the sound insulation performance becomes worse.

When the frequency is far lower than the coincidence frequency region, the sound transmission of single-layered panel is mainly forced transmission, and the sound insulation is not sensitive to the structural loss factor. When the frequency is

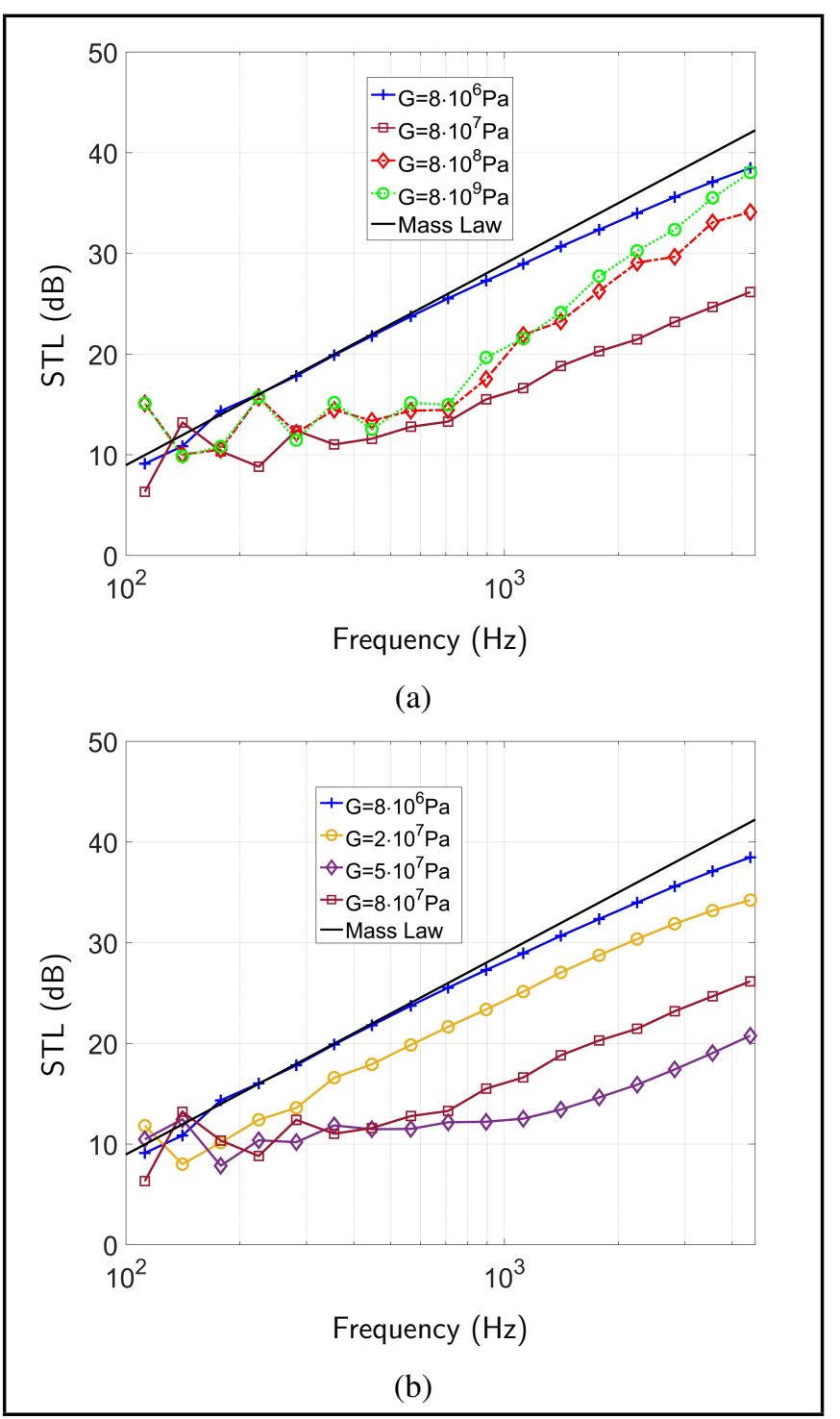

Figure 5. Influence of shear modulus variation of core layer on STL (1.4 mm $\mathrm{Al}+13.2 \mathrm{~mm}$ Honeycomb $+1.4 \mathrm{~mm} \mathrm{Al}$, surface density $8.51 \mathrm{~kg} / \mathrm{m}^{2}$ ).

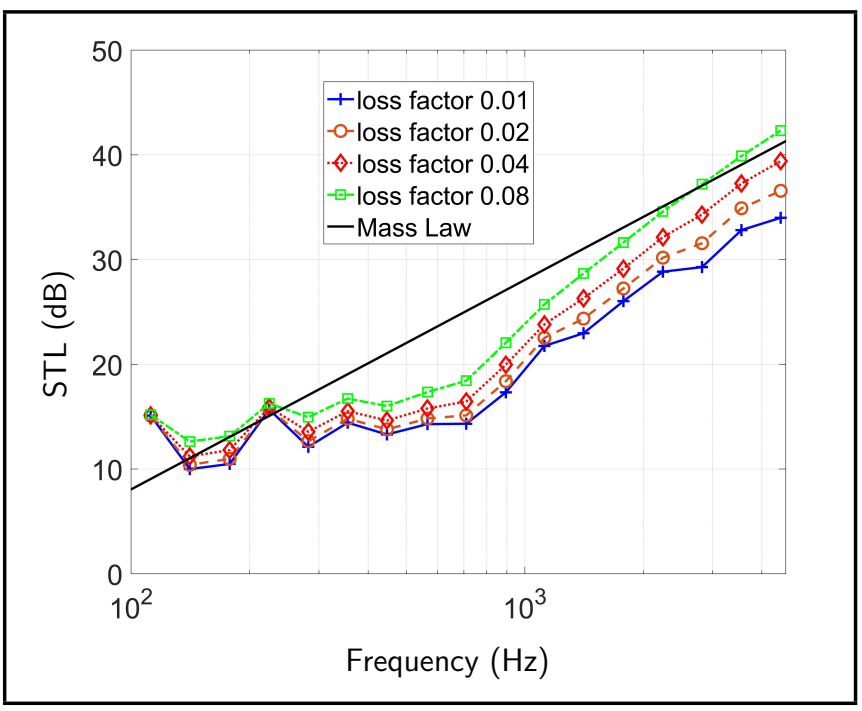

Figure 6. Influence of loss factor variation of core layer on STL (1.4 mm Al $+13.2 \mathrm{~mm}$ Honeycomb $+1.4 \mathrm{~mm} \mathrm{Al}$, surface density $8.51 \mathrm{~kg} / \mathrm{m}^{2}$ ). 


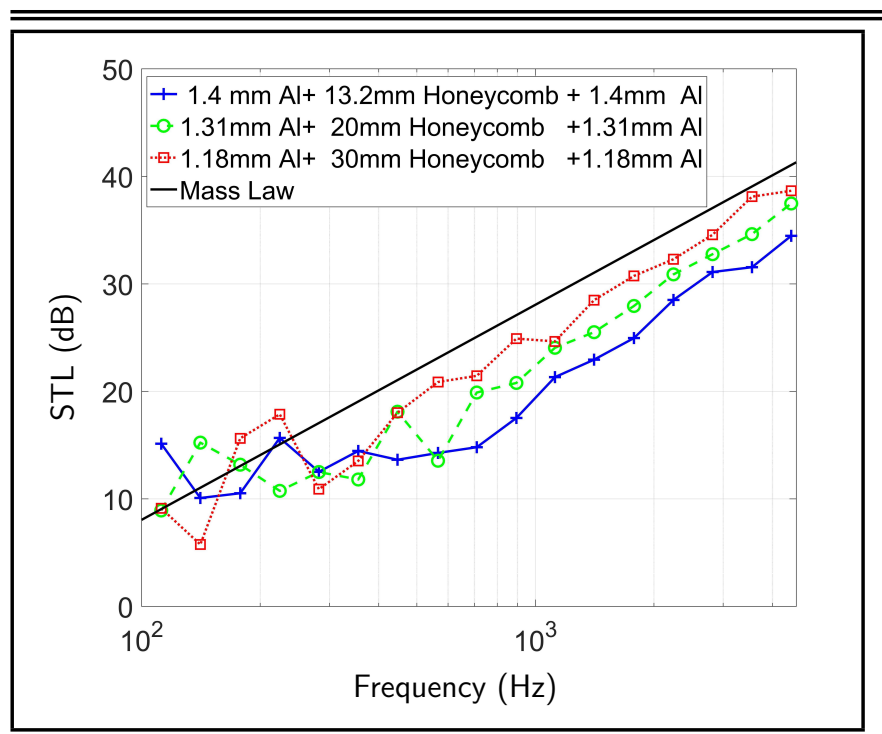

Figure 7. Influence of thickness variation of core layer on STL (surface density $8.51 \mathrm{~kg} / \mathrm{m}^{2}$ ).

above the coincidence frequency region, the loss factor has a significant influence on the sound insulation performance of single-layered panel. Unlike the single-layered panel, sandwich plates are sensitive to loss factor over the entire frequency range of interest. The structural loss factors are $0.01,0.02$, 0.04 and 0.08 , respectively. Other parameters used in the calculation follow the honeycomb sandwich plate A. As shown in Fig. 6, for every $100 \%$ increase in loss factor, this improves the sound insulation by $2 \mathrm{~dB}$ within most of the frequency range calculated, especially above $800 \mathrm{~Hz}$.

The influence of thickness variation of the core layer on STL is shown in Fig. 7. The total surface density is $8.51 \mathrm{~kg} / \mathrm{m}^{2}$. The thicknesses of the sheets and the aluminum honeycomb core are $1.4 \mathrm{~mm}+13.2 \mathrm{~mm}+1.4 \mathrm{~mm}, 1.31 \mathrm{~mm}+20 \mathrm{~mm}+$ $1.31 \mathrm{~mm}, 1.18 \mathrm{~mm}+30 \mathrm{~mm}+1.18 \mathrm{~mm}$. The sound insulation increases with the increase of the core thickness at most frequencies, especially above $500 \mathrm{~Hz}$. As the sandwich plate becomes hard enough, the sound insulation of the sandwich plate with a thick core becomes worse in the low frequency, and the advantage of increasing core thickness is not obvious.

Through the above research, the STL of honeycomb sandwich plate is lower than that of a homogeneous plate of equivalent mass, up to $10 \mathrm{~dB}$. The sandwich composite structure can realize lightweight and high static stiffness, but if the design is not good, its acoustic performance will be very poor. To get a sandwich plate with sound insulation performance close to the mass law, the shear modulus of the core layer must be in a suitable range and the structure loss factor should be as large as possible.

\section{EFFECT OF ACOUSTIC RADIATION TERMS ON STL}

The assumption of the blocked sound pressure, or alternatively speaking, ignoring sound radiation terms $2 p^{t}$, is somehow reasonable for relatively heavy and damping plates. For sandwich plates with honeycomb and foam cores, this assumption is worth examining for the prediction of STL. In order to study the effects of acoustic radiation terms $2 p^{t}$ on STL, variations of structure modal admittance considering radiation and ignoring radiation are deduced, and the variations of structure modal admittance lead to variations of STL on a single-layered panel and a honeycomb plate. The discrepancies of STL are obtained by subtracting the values of ignoring radiation from the values of considering radiation, then the discrepancies of STL are studied.

\subsection{Single-layered Panel}

The effect of thickness of carbon fiber panel and aluminum panel on the discrepancies of STL is shown in Fig. 8. The dimensions of the panels used in calculation are $1200 \mathrm{~mm} \times 1200 \mathrm{~mm}$. The Young modulus of the carbon fiber panel and aluminum panel are $5 \cdot 10^{10} \mathrm{~Pa}$ and $7.1 \cdot 10^{10} \mathrm{~Pa}$. The loss factors selected for the two types of panels are all $1 \%$. The thicknesses of the two types of panels are: $0.25 \mathrm{~mm}$, $0.5 \mathrm{~mm}$ and $1 \mathrm{~mm}$, respectively. For the above two types of single-layered panels, prediction results show that thickness has a great influence on the discrepancy of STL, and the discrepancies decrease with an increase in panel thickness. Using the discrepancy of STL less than $3 \mathrm{~dB}$ as a boundary, the influence of acoustic radiation terms on the aluminum panel or the single-layered panel with higher surface density can be negligible. For the carbon fiber panel, the influence can be ignored when the thickness of the panel exceeds $0.5 \mathrm{~mm}$. Therefore, in most cases, the influence of acoustic radiation terms on STL of single-layered panel can be ignored.

\subsection{Honeycomb Sandwich Plate}

The dimensions of the plates used in the calculation are $1200 \mathrm{~mm} \times 1200 \mathrm{~mm}$. Other parameters used in the calculation follow the honeycomb sandwich plate A, except when noted otherwise. The influence of shear modulus, surface density, core thickness and loss factor on the discrepancies of STL caused by sandwich plates ignoring sound radiation terms was discussed.

\subsubsection{Effect of shear modulus}

When the shear modulus of different core layer varies greatly, it is necessary to study the effect of shear modulus on acoustic radiation. The effect of shear modulus variation on discrepancies of STL is shown in Fig. 9. The core shear modulus are $8 \cdot 10^{6} \mathrm{~Pa}, 8 \cdot 10^{7} \mathrm{~Pa}, 8 \cdot 10^{8} \mathrm{~Pa}$ and $8 \cdot 10^{9} \mathrm{~Pa}$, respectively. In the whole frequency domain, the discrepancies of STL fluctuate significantly. The reason this happens is that the bending stiffness of the honeycomb sandwich plate is much higher than that of the homogeneous single-layered panel with the same weight, the high bending stiffness leads to the decrease of modal density, and the effect of single mode on acoustic radiation is more significant.

When the shear modulus is low $\left(8 \cdot 10^{6} \mathrm{~Pa}\right)$, the upper and lower panels are well decoupled, it is equivalent to a double plate, and the sound radiation has little effect on the sound insulation. However, when the shear modulus increases to $8 \cdot 10^{7} \mathrm{~Pa}$, the discrepancies of STL increase dramatically, and discrepancies have a maximum effect of $4.5 \mathrm{~dB}$ at coincidence frequency. When the shear modulus continues to increase $\left(8 \cdot 10^{8} \mathrm{~Pa}\right)$, the discrepancies of STL fluctuate significantly below coincidence frequency, and have a maximum effect of $5 \mathrm{~dB}$. When the shear modulus increases to $8 \cdot 10^{9} \mathrm{~Pa}$, the two sheets and the core layer are strongly connected and behave as a single-layered panel. Thus, the discrepancies decreased, so did the fluctuation range. At this point, increasing the shear modulus of the core layer has little influence on the discrepancies of STL. 


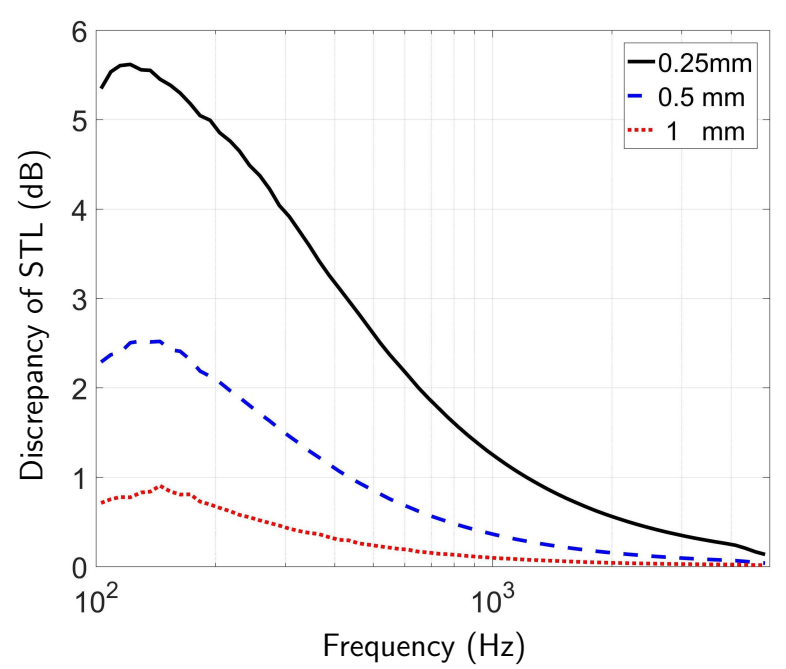

(a)

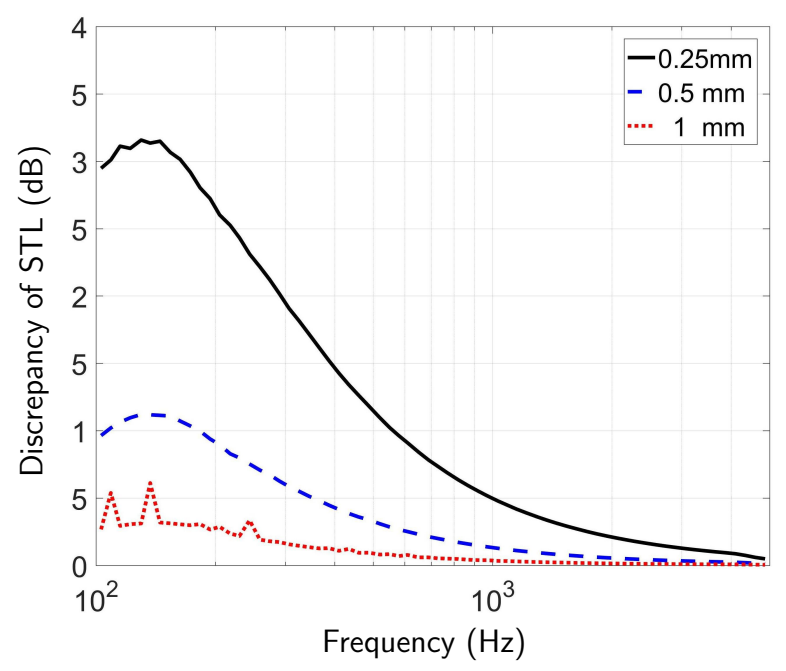

(b)

Figure 8. Effect of panel thickness variation on discrepancy of STL (a) Carbon fiber panel (surface density $0.4 \mathrm{~kg} / \mathrm{m}^{2}, 0.8 \mathrm{~kg} / \mathrm{m}^{2}, 1.6 \mathrm{~kg} / \mathrm{m}^{2}$ ); (b) Aluminum panel (surface density $0.675 \mathrm{~kg} / \mathrm{m}^{2}, 1.35 \mathrm{~kg} / \mathrm{m}^{2}, 2.7 \mathrm{~kg} / \mathrm{m}^{2}$ ).

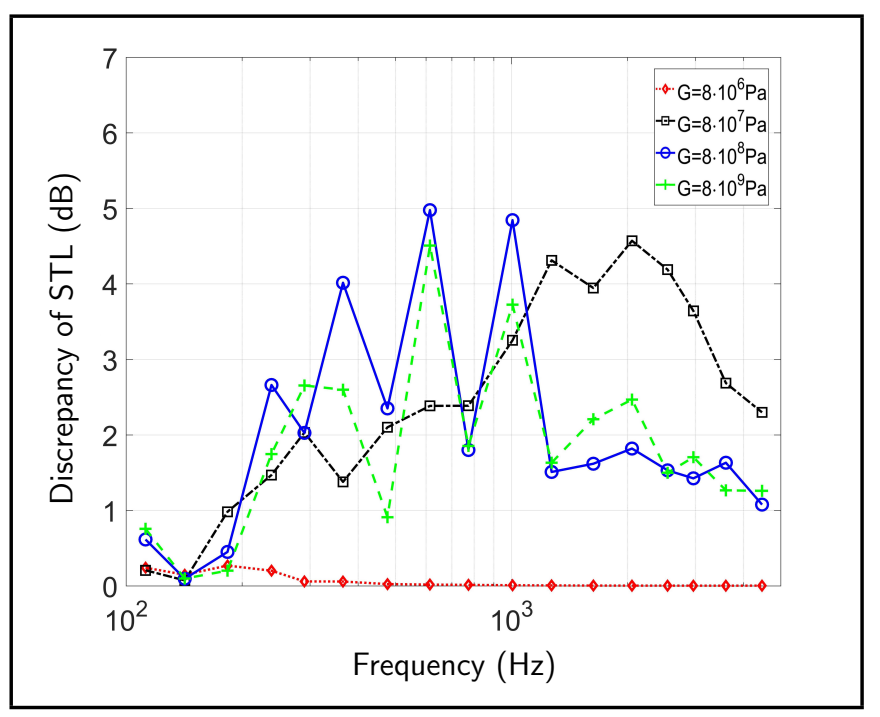

Figure 9. Effect of shear modulus variation on discrepancy of STL $(1.4 \mathrm{~mm}$ $\mathrm{Al}+13.2 \mathrm{~mm}$ Honeycomb + $1.4 \mathrm{~mm} \mathrm{Al}$, surface density $\left.8.51 \mathrm{~kg} / \mathrm{m}^{2}\right)$.

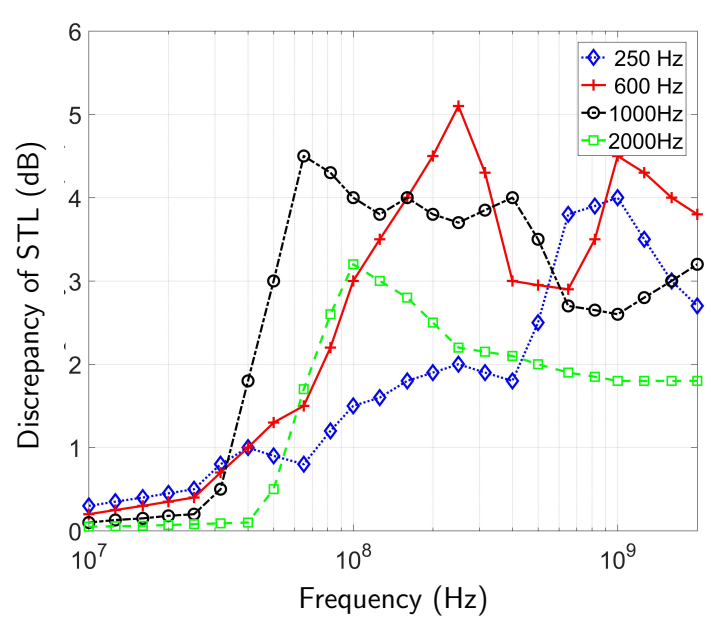

Figure 10. Effect of shear modulus variation on discrepancy of STL at a single frequency $(1.4 \mathrm{~mm} \mathrm{Al}+13.2 \mathrm{~mm}$ Honeycomb $+1.4 \mathrm{~mm} \mathrm{Al}$, surface density $\left.8.51 \mathrm{~kg} / \mathrm{m}^{2}\right)$.

The effect of shear modulus on discrepancies of STL at a single frequency is further analyzed in Fig. 10. When the shear modulus is less than $5 \cdot 10^{7} \mathrm{~Pa}$, the discrepancies decrease slightly with the increase of frequency and are generally in a negligible range. When the shear modulus exceeds $1 \cdot 10^{8} \mathrm{~Pa}$, the discrepancies near the coincidence frequency region are higher than the other frequency. In a word, the effect of sound radiation on the sound insulation near the coincidence frequency region is greater than that of other frequencies.

\subsubsection{Effect of surface density}

The effect of surface density variation on discrepancies of STL is illustrated in Fig. 11. The total surface densities of the honeycomb sandwich plates are: $8.51 \mathrm{~kg} / \mathrm{m}^{2}, 10.13 \mathrm{~kg} / \mathrm{m}^{2}$, $11.75 \mathrm{~kg} / \mathrm{m}^{2}$, respectively. The thicknesses of the sheets and the aluminum honeycomb core are: $1.4 \mathrm{~mm}+13.2 \mathrm{~mm}+$ $1.4 \mathrm{~mm}, 1.7 \mathrm{~mm}+13.2 \mathrm{~mm}+1.7 \mathrm{~mm}, 2.0 \mathrm{~mm}+13.2 \mathrm{~mm}$ $+2.0 \mathrm{~mm}$, respectively. In the whole frequency domain, the discrepancies of STL fluctuate significantly. The discrepancies increase gradually with the increase of frequency, reach its peak value at the coincidence frequency region, and the discrepancies decrease with the increase of frequency above the coincidence frequency region. The variation of surface density has a significant influence on the discrepancies of STL, with the increase of surface density, the discrepancies decrease and fluctuations of the discrepancies significantly decrease. Therefore, large surface density can significantly reduce acoustic radiation.

To study the impact of different face sheet materials on sound insulation, the total surface densities of the honeycomb sandwich plates are: $8.51 \mathrm{~kg} / \mathrm{m}^{2}$, and the thicknesses of steel face sheets and carbon fiber sheets are $0.48 \mathrm{~mm}$ and $3.15 \mathrm{~mm}$. It is interesting to observe that the discrepancies of the sandwich plate with aluminum face sheets are much worse, as shown in Fig. 12.

\subsubsection{Effect of core thickness}

The effect of core thickness variation on discrepancies of STL is shown in Fig. 13. The thicknesses of the core used in calculation are $13.2 \mathrm{~mm}, 20 \mathrm{~mm}$, and $30 \mathrm{~mm}$, respectively. To make the plates having the same surface density $\left(8.51 \mathrm{~kg} / \mathrm{m}^{2}\right)$, the face sheets are set to $1.4 \mathrm{~mm}, 1.31 \mathrm{~mm}$, and $1.18 \mathrm{~mm}$, 


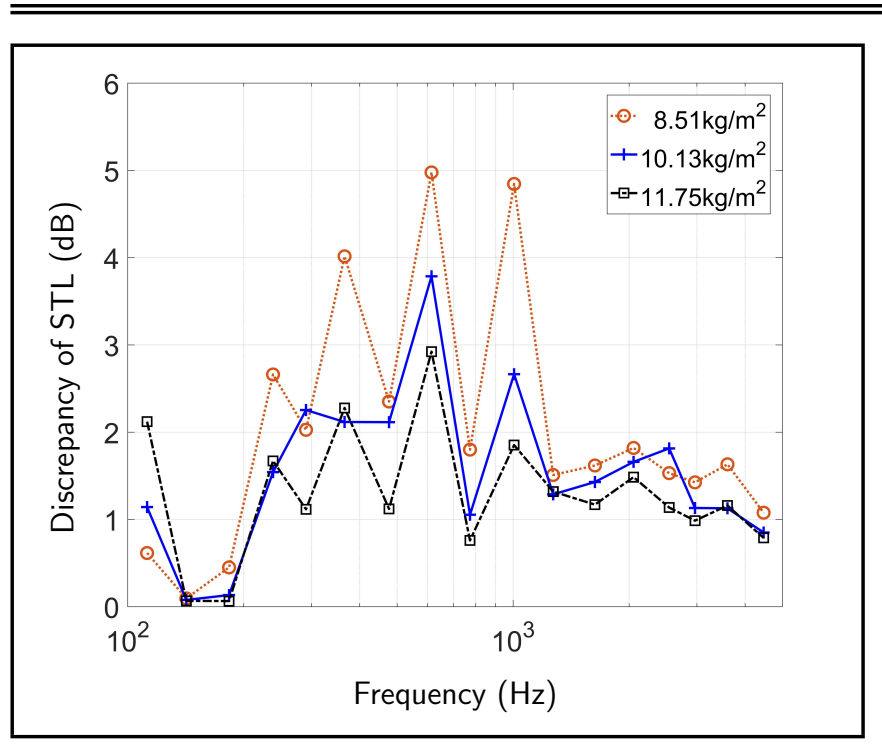

Figure 11. Effect of surface density variation on discrepancy of STL.

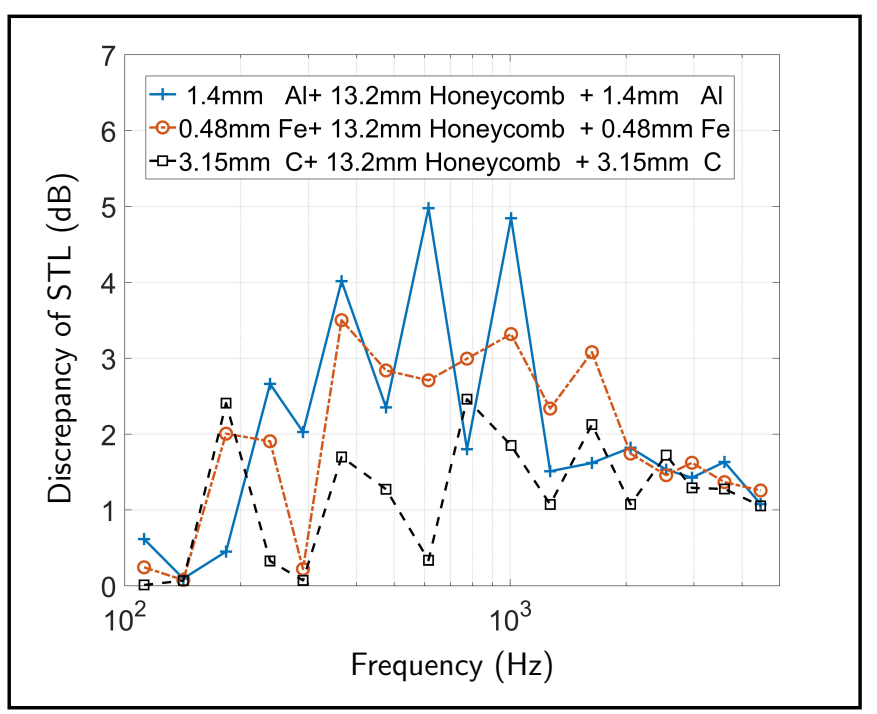

Figure 12. Effect of different face sheets on discrepancy of STL (surface density $8.51 \mathrm{~kg} / \mathrm{m}^{2}$ ).

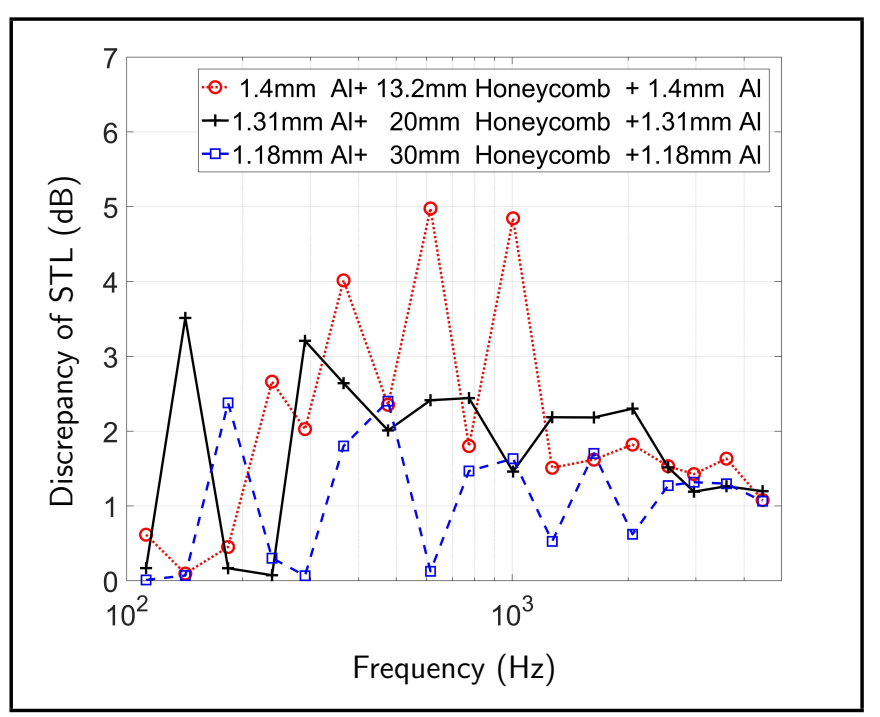

Figure 13. Effect of core thickness variation on discrepancy of STL (surface density $8.51 \mathrm{~kg} / \mathrm{m}^{2}$ ).

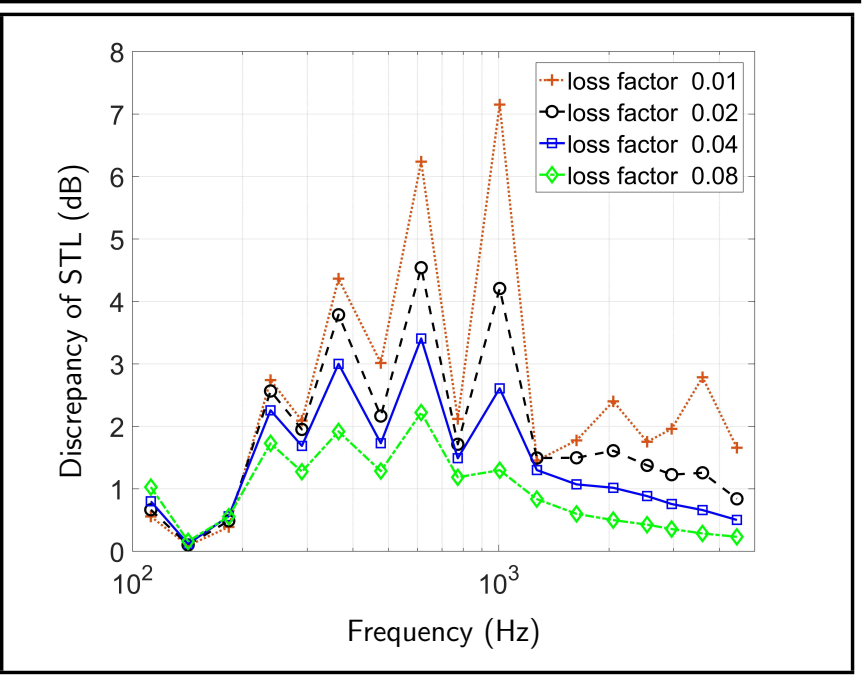

Figure 14. Effect of loss factor variation on discrepancy of STL (1.4 mm Al $+13.2 \mathrm{~mm}$ Honeycomb $+1.4 \mathrm{~mm} \mathrm{Al}$, surface density $8.51 \mathrm{~kg} / \mathrm{m}^{2}$ ).

respectively. The variation of core thickness has significant influence on discrepancies of STL, with the increase of core thickness, the discrepancies decrease and fluctuations of the discrepancies significantly decrease. For a sandwich honeycomb plate with a surface density of $8.51 \mathrm{~kg} / \mathrm{m}^{2}$, the discrepancies reach its peak value of $5 \mathrm{~dB}$ at the coincidence frequency region. When the core thickness increases to a certain thickness, the discrepancies can be ignored. Therefore, increasing the thickness of the core layer can significantly reduce the influence of acoustic radiation.

\subsubsection{Effect of loss factor}

The effect of loss factor variation on discrepancies of STL is shown in Fig. 14. The loss factors are: 0.01, 0.02, 0.04 and 0.08 , respectively. The variation of the loss factor has significant influence on the discrepancy of STL, the discrepancies and the fluctuations of discrepancies significantly decrease with the increase of core loss factor. When the loss factor is 0.01 , the discrepancies reach its peak value of $7 \mathrm{~dB}$. When the loss factor is 0.08 , the discrepancies decrease to $1 \sim 2 \mathrm{~dB}$. Therefore, large loss factor can significantly reduce acoustic radiation.

Different from the single-layered panel, the sound radiation terms have great influence on the STL of sandwich plates, especially around the coincidence frequency. For sandwich plates with honeycomb and foam cores, sound radiation terms cannot be ignored, with or without considering the acoustic radiation could result in the difference of $7 \mathrm{~dB}$ in maximum, and $3 \sim 4 \mathrm{~dB}$ on average.

\section{CONCLUSIONS}

Based on a sixth-order differential equation governing the flexural vibration of sandwich plates, the theoretical formula of STL of honeycomb foam sandwich plates was derived by the modal summation approach. The method is an efficient tool to predict acoustic properties of sandwich plate and can be used to analyze the influence of material and structural parameters of honeycomb and foam sandwich plates on STL rapidly. Through comparison and analysis, it is found that shear modulus and loss factor of the core layer play important roles on the STL of honeycomb and foam sandwich plates. When the shear modulus of the core layer is low, the sound insulation 
agrees well with the mass law over a large frequency range. However, when the shear modulus of the core layer increases, sound insulation can be much worse than mass law. If the shear modulus continues to increase and becomes very high, then the two sheets and core layer are strongly connected. The sound insulation increases with the increase of shear modulus, but is still lower than the level of the mass law.

Unlike a single leaf panel, the analytical model showed that the STL of a finite sandwich plate with honeycomb and foam cores could be very sensitive to the effective loss factors of sandwich structures in the low and middle frequency range. The effective loss factor includes the damping of structures and the damping due to acoustic radiation as well. This implies that the commonly-used assumption of the blocked sound pressure, or alternatively speaking, ignoring sound radiation terms, may not be suitable for sandwich plates. For typical sandwich plates, it is found that ignoring sound radiation terms could reach $5 \mathrm{~dB}$ less for the predicted STL in the frequency range of interest. Discrepancies of STL caused by ignoring sound radiation terms are closely related to frequency, surface density, and shear modulus of the core layer.

\section{ACKNOWLEDGEMENTS}

The authors would like to deliver their sincere thanks to NSFC with Grant Nos.11874034 and Taishan Scholar Program of Shandong (No.ts201712054) for its generous funding for this project.

\section{REFERENCES}

1 Kurtze, G., and Watters, B. New wall design for high transmission loss or high damping, J. Acoust. Soc. Am, 31(6), 739-748, (1959). https://dx.doi.org/10.1121/1.1907780

2 Dym, C.L., and Lang, M.A. Transmission of sound through sandwich panels, J. Acoust. Soc. Am, 56(5), 1523-1532, (1974). https://dx.doi.org/10.1121/1.1903474

3 Lang, M.A., and Dym, C.L. Optimal acoustic design of sandwich panels, J. Acoust. Soc. Am, 57(6), 1481-1487, (1975). https://dx.doi.org/10.1121/1.380588

4 Ford, R.D., Lord, P., and Walker, A.W. Sound transmission through sandwich constructions, J. Acoust. Soc. Am, 5(1), 9-21, (1967). https://dx.doi.org/10.1016/0022$460 \times(67) 90173-3$

5 Nilsson, A.C. Some acoustical properties of floatingfloor constructions, J.Acoust. Soc. Am, 61(6), 1533-1539, (1977). https://dx.doi.org/10.1121/1.381465

6 Nilsson, A.C. Wave propagation in and sound transmission through sandwich panels, J. Sound. Vib., 138(1), 73-94, (1990). https://dx.doi.org/10.1016/0022-460X(90)90705-5

7 Thamburaj, P., and Sun, J.Q. Effect of material anisotropy on the sound and vibration transmission loss of sandwich aircraft structures, J. Sandwich Struct. Mater., 1(1), 76-92, (1999). https://dx.doi.org/10.1177/109963629900100105

8 Thamburaj, P., and Sun, J.Q. Effect of material and geometry on the sound and vibration transmission across a sandwich beam, J. Vib. Acoust., 123(2), 205-212, (2001). https://dx.doi.org/10.1115/1.1343083
9 Kihlman, T., Nilsson, A.C. The effects of some laboratory designs and mounting conditions on reduction index, J. Sound. Vib., 24, 349-364, (1972). https://dx.doi.org/10.1115/1.1343083

10 Takahashi, D. Sound radiation from periodically connected double-plate structures, J. Sound. Vib., 90(4), 541-557, (1983). https://dx.doi.org/10.1016/0022-460x(83)90810-6

11 Lee, C., and Kondo, K. Noise transmission loss of sandwich plates with viscoelastic core, 40th Structures, Structural Dynamics, and Materials Conference and Exhibit, St Louis, MO, (1999). https://dx.doi.org/10.2514/6.1999-1458

12 Lok, T.S., and Cheng, Q.H. Bending and forced vibration response of a clamped orthotropic thick plate and sandwich panel, J. Sound. Vib., 245(1), 63-78, (2001). https://dx.doi.org/10.1006/jsvi.2000.3543

13 Lok, T.S., and Cheng, Q.H. Free and forced vibration of simply supported, orthotropic sandwich panel, Computers-Structures, 79(3), 301-312, (2001). https://dx.doi.org/10.1016/s0045-7949(00)00136-X

14 Du, S.W., An, F.Y., and Liu, B.L. On the sound transmission loss of finite plates with constrained viscoelastic layer, Applied Acoustics, 149, 32-38, (2019). https://dx.doi.org/10.1016/j.apacoust.2019.01.010

15 Kumar, S., Feng, L.P., and Orrenius, U. Predicting the sound transmission loss of honeycomb panels using the wave propagation approach, Acta Acustica united with Acustica, 97(5), 869-876, (2011). https://dx.doi.org/10.3813/AAA.918466

16 Qian, Z.C., Chang, D.Q., and Liu, B.L. Prediction of sound transmission loss for finite sandwich panels based on a test procedure on beam elements, J. Vib. Acoust., 135(6), 1-9, (2013). https://dx.doi.org/10.1115/1.4023842

17 Liu, B.L., and Li, X. Noise transmission and absorption of lightweight structures: an overview and experience, distinguished plenary lecture, 26th International Congress on Sound and Vibration, Montreal, (2019).

18 Fu, T., Chen, Z.B., Yu, H.Y., Li, C.F., and Liu, X.X. Optimization of sound transmission loss characteristics of orthogonally stiffened plate, J. Theor. Comp. Acoust, 26(4), 1-17, (2018). https://dx.doi.org/10.1142/S0218396X18500108

19 Nilsson, A.C., and Liu, B.L. Prediction of some vibroacoustic properties of sandwich plates with honeycomb and foam cores, J. Acoust. Soc. Am, 144(3), 1600-1614, (2018). https://dx.doi.org/10.1121/1.5055233

${ }^{20}$ Li, W.L., and Gibeling, H.J. Determination of the mutual radiation efficiencies of a rectangular panel and their impact on the radiated sound power, J. Sound. Vib., 229(5), 12131233, (2000). https://dx.doi.org/10.1006/jsvi.1999.2592

21 Liu, B.L., and Feng, L.P. Sound transmission through curved aircraft panels with stringer and ring frame attachments, J. Sound. Vib., 300(3-5), 949-973, (2007). https://dx.doi.org/10.1016/j.jsv.2006.09.008

22 Tang, Z.Z. Research on sound insulation of aluminum foam sandwich plate, M.D. thesis. 